\title{
Interrupções em projetos de engenharia consultiva em cenário de desestruturação organizacional
} Interruptions in consulting engineering projects in a scenario of organizational disruption

\section{Daniel Figaro Pinca ${ }^{1}$; Diane Simon Rozzetto ${ }^{2}$}

${ }^{1}$ Escola de Engenharia de São Carlos - Engenheiro Civil - Av. Trabalhador São-Carlense, 400 - 13566-590 - São Carlos, SP, Brasil < danielpinca@hotmail.com>

${ }^{2}$ Escola Superior de Agricultura "Luiz de Queiroz" - Doutoranda em Genética e Melhoramento Vegetal - Av. Pádua Dias, 11 - Cx. Postal 9 - $13418-900$ - Piracicaba, SP, Brasil

\section{Resumo}

A engenharia consultiva no Brasil experimentou, no início do século XXI, um grande crescimento advindo da pujante demanda por projetos de infraestrutura. Na esteira do acelerado desenvolvimento econômico e da grande injeção de capital - através de financiamentos públicos fartos e facilitados - armou-se um cenário de descuido com execuções realizadas sem planejamento prévio. Foram relegadas estratégias de planejamento, aplicação de ferramentas de gerenciamento consagradas e as boas práticas administrativas. Ocorreram problemas de paralisações delongadas em decorrência da mudança repentina de ambiente políticoeconômico, do envolvimento empresarial em atividades causadoras de insegurança jurídica e esvaziamento dos financiamentos públicos e sem determinação de prazos de vários projetos brasileiros. Neste cenário evidencia-se a importância do bom planejamento e da boa gestão, garantindo que o risco de ocorrência da paralisação seja conhecido, diminuído e seus possíveis efeitos mitigados. O objetivo foi orientar o gestor de projeto na escolha das melhores e mais adequadas ferramentas de gestão e evidenciar a necessidade da correta utilização das mesmas. Por meio de estudo de caso sobre fato passado em projeto executivo de saneamento, é trazido à luz que a ausência de elementos básicos da gestão de projeto, principalmente em fase inicial, contribuiu para a maior exposição aos riscos organizacionais e no maior impacto decorrente das paralisações do projeto. A falta de elementos subsidiários ao adequado planejamento, tais como: Estrutura Analítica de Projeto [EAP]; Estrutura Analítica de Riscos [EAR]; "Cronograma detalhado" e "Coleta de requisitos financeiros" foram determinantes para o fracasso no atingimento dos objetivos do projeto.

Palavras-chave: adversidades em projetos, construção civil, consultoria, infraestrutura, paralisação de projeto

\begin{abstract}
The advisory engineering in Brazil experienced a great growth coming from the growing demand for infrastructure projects by the beginning of the 21 st century. In the wake of accelerated economic development and large capital injection a scenario of oversight with over-accelerated execution has set in by crowded and facilitated public funding. Strategies of planning, application of established management tools and good administrative practices were relegated. There were problems of stoppage as a result of the sudden change in the political-economic environment, corporate involvement in activities that caused legal uncertainty, decrease of public financing and indetermination of deadlines of several Brazilian projects. This scenario highlights the importance of good planning and good management, ensuring that the risk of occurrence of the shutdown is known, diminished and its effects mitigated. The objective was to guide the project manager to choose the best and most appropriate management tools and to highlight the need of the correct use. A case study was conducted in an executive sanitation project and the absence of basic elements of project management, especially in the initial phase, contributed to the greater exposure to organizational risks and the greater impact resulting from the project shutdowns. The lack of subsidiary elements to the appropriate planning, such as, Work Breakdown Structure [WBS]; Risk Breakdown Structure [RBS]; detailed schedule and collection of financial requirements were decisive for the failure to achieve the objectives of the project.
\end{abstract} Keywords: adversities in projects, civil construction, consulting, infrastructure, project stoppage 


\section{Introdução}

O mercado nacional da engenharia consultiva, em especial de projetos de saneamento básico, energia elétrica e logística, viveu tempos de grande crescimento e aumento de faturamento entre a segunda metade do ano de 2004 até 2011. Segundo Sabbatini (2011), a retomada do crescimento econômico observada no Brasil (após a segunda metade do ano de 2004) pode ser especialmente atribuída a massiva recuperação das taxas de investimento. Como fonte de investimento público, foi lançado, em janeiro de 2007, o primeiro programa do governo federal denominado Programa de Aceleração do Crescimento [PAC] que abarcava um conjunto de políticas econômicas objetivando acelerar o crescimento econômico.

O PAC 1 previu investimentos em infraestrutura da ordem de 411 bilhões de reais entre 2007 e 2010 frente a investimentos da ordem de 177 bilhões de reais entre 2002 e 2005 (Sabbatini, 2011). Tais investimentos demandaram numerosos serviços de engenharia e explicaram o crescimento do segmento de engenharia consultiva no referido período. Este crescimento também foi aprofundado pela expansão dos investimentos destinados à preparação dos eventos esportivos sediados pelo país em 2014 e 2016 (Sabbatini, 2011).

O mesmo movimento de fomento ao setor de engenharia consultiva, observado no PAC 1 , se repetiu em 2014 à luz dos investimentos anunciados para o PAC 2. Assim como todos os segmentos que compõem os 955 bilhões de reais em investimentos previstos para 2014, os serviços de empresas de engenharia consultiva (em especial saneamento básico) foram significativamente demandados (Sabbatini, 2011).

Uma parcela importante das empreiteiras do setor da construção civil pesada nacional (infraestrutura) com relações comerciais e contratuais com a empresa estatal petrolífera foi atingida, a partir de março de 2014, pelo desenrolar da Operação Lava Jato que, segundo o Ministério Público Federal [MPF] (2017) constitui na maior investigação de corrupção e lavagem de dinheiro atuante no Brasil.

Uma dimensão do impacto da citada operação pode ser dada pelo volume estimado de recursos financeiros desviados da empresa, que são da ordem de bilhões de reais; além da grande expressão político-econômica dos suspeitos envolvidos neste esquema de corrupção (MPF, 2017).

Pela legislação penal vigente no Brasil, as empresas denunciadas na ação penal passaram a serem consideradas rés e consequentemente não idôneas e tiveram seus nomes incluídos na lista/ cadastro de inidôneos, com impossibilidade de participar de licitações realizadas pela Administração Pública Federal, nos termos do art. 46 da Lei n ${ }^{\circ} 8.443 / 92$ Tribunal de Contas da União [TCU]
(2017). Consequentemente, os financiamentos públicos foram cessados e/ou os montantes disponibilizados foram bloqueados - e indiretamente até os investimentos privados foram esgotados por questões de imagem mercadológica dos envolvidos. Assim, as empreiteiras não tiveram condições financeiras (via captação de recursos de financiamento) para suportar os projetos que haviam sido iniciados; mais ainda: parte de seu quadro técnico/ alta gerência executiva estavam criminalmente envolvidos na Operação Lava Jato e tiveram seus afastamentos compulsórios.

Tem-se aí as particularidades e dificuldades no gerenciamento das paralisações do projeto em situações atípicas de desestruturação caótica das organizações - onde há a falta de previsões concretas acerca da continuidade do projeto (ou da mudança de ritmo de andamento, por exigência do "sponsor") - quer seja por falta de orçamento do "sponsor"; perda de apoio da alta gerência do cliente ou por perda de recursos humanos do corpo técnico de um "stakeholder" chave.

À luz dos acontecimentos narrados, os elementos consagrados da gestão de projetos foram destacados e contextualizados na problemática mais recentemente enfrentada pelos atores da engenharia nacional atual: a desestruturação organizacional, decorrente de alterações de ambiente. O objetivo deste estudo foi documentar e evidenciar a importância da escolha das melhores e mais adequadas ferramentas de gestão e alertar para a necessidade da correta utilização das mesmas, de modo a minimizar os efeitos negativos de paralizações impostas em ambiente de negócios adverso.

\section{Material e Métodos}

\section{Contextualização}

Foi realizado um estudo de caso ex-post facto (a partir do fato passado) em uma empresa global de projetos e consultoria para ambientes naturais e construídos (infraestrutura civil, com sede e operações centralizadas em São Paulo/SP). O trabalho tratou de uma análise ampla dos acontecimentos e crítica do ferramental desenvolvido à época para o desenvolvimento de um projeto executivo de sistema de coleta, afastamento e tratamento de esgoto na área de saneamento básico, iniciado em junho de 2014 e paralisado em maio de 2015 e, posteriormente, foi compulsoriamente cancelado.

O projeto que motivou o trabalho estava inserido no município do Estado de Mato Grosso - no contexto dos investimentos do PAC 2 - com estudos e projetos executivos do Sistema de Esgotamento Sanitário [SES] (coletores tronco, estações elevatórias linhas de recalque e estações de tratamento de esgoto), compreendendo: desenhos de engenharia, especificações técnicas de peças e equipamentos, além de quantitativos de materiais necessários à obra. $\mathrm{O}$ mesmo foi celebrado entre a 
companhia de saneamento local (empresa privada atuando através de concessão pública municipal) e uma empresa do ramo de consultoria especializada em elaboração de estudos e projetos de infraestrutura civil de duração legal prevista até o final de dezembro de 2015.

\section{Delimitação da unidade-caso}

O projeto em questão teve seu prazo de execução fixado em contrato com duração de um ano e seis meses (18 meses consecutivos) - prazo este estimado na fase de elaboração de proposta técnica, que precede o contrato assinado. Foi contratado pela modalidade empreitada por preço global no valor aproximado de 7,4 milhões de reais (Montante deflacionado pelo Índice Geral de Preços do Mercado da Fundação Getúlio Vargas [IGP-M/FGV] - valor à época de $\mathrm{R} \$ 6,3$ milhões). O escopo foi definido pelo Estudo de Concepção préexistente (peça de engenharia consultiva fornecida e préaprovada pelo cliente, onde as principais características gerais, para os dimensionamentos e projetos detalhados são apresentados); que, por sua vez, seguiu as premissas e requisitos do Plano Diretor aprovado para o município (instrumento que visa regular a ocupação espacial, além de proporcionar sustentabilidade no desenvolvimento da região). O critério de medição e pagamento dos trabalhos realizados (com apuração em periodicidade mensal) era por entrega efetuada, com pagamento parcial no ato da mesma e liberação do restante quando da aprovação técnica pelo cliente, na proporção de $60 \%$ na apresentação do projeto e $40 \%$ na aprovação.

Importante ressaltar que no contrato do projeto objeto não houve montagem da Estrutura Analítica do Projeto [EAP] seguindo o princípio da estruturação dos trabalhos por entrega de produtos (Maximiano, 2014).

Para a execução dos pacotes de trabalho definidos no contrato a empresa projetista optou pela montagem completa de um escritório local situado nas dependências do cliente. Os projetos seriam desenvolvidos através de subcontratações de consultores especializados: projetistas hidromecânicos; elétricos; estruturais; processos de tratamento de esgoto e equipes de levantamento topográfico. A composição básica do escritório regional, dedicado exclusivamente ao projeto, era dois engenheiros civis plenos - um com atribuição de coordenador geral local - e um engenheiro ambiental júnior.

A empresa projetista em estudo seguia a estrutura de matricial projetizada com o gerente do projeto do tipo peso pesado (locado fisicamente na matriz em São Paulo capital, com deslocamentos esporádicos ao município do projeto) e com mais autoridade sobre a equipe do que os gerentes funcionais (Maximiano, 2014).

Ainda segundo Maximiano (2014), esta estrutura é a mais indicada quando se faz necessário o compartilhamento, entre áreas funcionais e seus recursos humanos, em projetos distintos; indicada também quando os recursos humanos são escassos, ou quando o vulto diminuto do projeto não justifica a organização independente. Neste projeto ocorriam duas dessas situações, a saber: i) necessidade de compartilhamento entre projetos diferentes de recursos humanos das áreas funcionais. Todo apoio administrativo e financeiro era desempenhado pela equipe localizada na matriz em São Paulo, assim como os consultores especializados que também eram compartilhados entre os projetos da companhia. ii) o porte do projeto não justificava uma organização independente, tanto em valor monetário inferior a dez milhões de reais - quanto em tempo de duração - mais breve que dois anos.

O projeto desenvolveu-se até março de 2015, quando houve alteração repentina no quadro de funcionários da alta gerência do cliente, culminando com a saída de dois funcionários-chave envolvidos diretamente nos trabalhos. Entre eles a engenheira sênior de projetos e o superintendente da área de infraestrutura a quem o projeto era subordinado. Os desligamentos foram sumários e novos funcionários não foram destacados para preencher as ocupações deixadas. A empresa projetista contratada foi apenas informada e não recebeu nenhum plano de continuidade e alteração do projeto.

No mês de abril de 2015 houve grandes alterações na situação financeira do cliente e, por solicitação explicita do mesmo, o ritmo de trabalho teve que ser diminuído. A paralisação completa dos trabalhos do projeto ocorreu no final de maio de 2015, com a desmobilização compulsória da equipe local dedicada ao projeto e o contrato não mais se desenvolveu. O pessoal envolvido foi alocado em outros projetos do portfólio da empresa projetista. O contrato passou por um período de total inatividade por parte de ambas as envolvidas (contratada e contratante), sem avanço algum nas tratativas até a data do fim contratado. Com o final do prazo contratual dezembro de 2015 - o setor jurídico da empresa projetista contratada assumiu todos os trâmites burocráticos legais para o destrato do contrato. Tal dissolução foi oficializada no primeiro trimestre de 2016.

\section{Coleta de dados}

Os dados analisados basearam-se em documentações produzidas na época da realização do projeto, sendo a tabela resumo do contrato celebrado e o cronograma aprovado (Gráfico de Gantt). A falta de outros materiais, como: Estrutura Analítica de Projeto; Estrutura Analítica de Riscos; planejamento de riscos foram objeto de discussão.

Apresentado o gráfico do tipo Gantt (Figura 1), na forma como foi utilizado no contrato, para representação do cronograma do projeto. Foram discriminados neste gráfico de Gantt apenas cada unidade física constituinte 
do futuro sistema de esgotamento sanitário inserido no escopo do projeto; não sendo estas, por sua vez, decompostas em itens mais específicos que fazem parte de todo o trabalho necessário para conclusão e entrega do pacote de trabalho (produto). Notou-se uma simplificação temerária do cronograma do projeto com a representação de cada unidade a ser projetada em apenas uma linha do gráfico de Gantt. Análise mais aprofundada e demais caraterísticas do gráfico foram abordados na seção seguinte.

\begin{tabular}{|c|c|c|c|c|c|c|c|c|c|c|c|c|c|c|c|c|c|c|c|}
\hline & \multicolumn{7}{|c|}{2014} & \multicolumn{12}{|c|}{2015} \\
\hline & jun & jul & ago & set & out & nov & dez & jan & fev & mar & $a b_{1}$ & $\mathrm{ma}$ & jur & jul & ago & set & out & nov & dez \\
\hline \multicolumn{20}{|l|}{ FASE 1} \\
\hline \multicolumn{20}{|l|}{ RA 1.1} \\
\hline \multicolumn{20}{|l|}{ RA 1.2} \\
\hline \multicolumn{20}{|l|}{ RPV 1.1} \\
\hline \multicolumn{20}{|l|}{ FASE 2} \\
\hline \multicolumn{20}{|l|}{ Sistema 1} \\
\hline \multicolumn{20}{|l|}{ ETE 1.1} \\
\hline \multicolumn{20}{|l|}{ EEE 1.1} \\
\hline \multicolumn{20}{|l|}{ IT 1.1} \\
\hline \multicolumn{20}{|l|}{ Sistema 2} \\
\hline \multicolumn{20}{|c|}{ ETE 2.1 (Adequações) } \\
\hline \multicolumn{20}{|l|}{ EEE 2.1} \\
\hline \multicolumn{20}{|l|}{ IT 2.1} \\
\hline \multicolumn{20}{|l|}{ Sistema 3} \\
\hline \multicolumn{20}{|l|}{ ETE 3.1} \\
\hline \multicolumn{20}{|l|}{ EEE 3.1} \\
\hline \multicolumn{20}{|l|}{ IT 3.1} \\
\hline \multicolumn{20}{|l|}{ Sistema 4} \\
\hline \multicolumn{20}{|l|}{ EEE 4.1} \\
\hline \multicolumn{20}{|l|}{ IT 4.1} \\
\hline Sistema 5 & & & & & & & & & & & & & & & & & & & \\
\hline ETE 5.1 & & & & & & & & & & & & & & & & & & & \\
\hline EEE 5.1 & & & & & & & & & & & & & & & & & & & \\
\hline IT 5.1 & & & & & & & & & & & & & & & & & & & \\
\hline Sistema 6 & & & & & & & & & & & & & & & & & & & \\
\hline ETE 6.1 & & & & & & & & & & & & & & & & & & & \\
\hline EEE 6.1 & & & & & & & & & & & & & & & & & & & \\
\hline IT 6.1 & & & & & & & & & & & & & & & & & & & \\
\hline Sistema 7 & & & & & & & & & & & & & & & & & & & \\
\hline ETE 7.1 & & & & & & & & & & & & & & & & & & & \\
\hline EEE 7.1 & & & & & & & & & & & & & & & & & & & \\
\hline IT 7.1 & & & & & & & & & & & & & & & & & & & \\
\hline
\end{tabular}

Legenda: Relatório de Análise [RA]; Relatório de Populações e Vazões [RPV]; Estação de Tratamento de Esgoto [ETE]; Estação Elevatória de Esgoto [EEE]; Interceptor de Esgoto (tubulação) [IT]

Figura 1. Cronograma geral do Projeto Sistema de Esgotamento Sanitário [SEE]

O contrato firmado entre o cliente (companhia de saneamento local) e a empresa projetista teve como parte constituinte uma estrutura em forma de tabela intitulada 'Quadro Resumo', que apresentava apenas as características principais do contrato celebrado de forma resumida e apenas com destaque para os pontos de responsabilidade de cada parte.

\section{Resultados e Discussão}

A bibliografia que versa sobre paralisações de projeto é carente no Brasil, com a maioria dos estudos concentrados no controle do cronograma e na estimativa de duração das tarefas. Porém, um problema não frequentemente abordado na literatura é a interrupção do projeto (por tempo determinado ou indeterminado) através de interferência e deliberação do "sponsor" (que eventualmente pode ser a alta administração do cliente). Este fato tornou o sucesso do projeto descrito ainda mais difícil, pois um dos principais fatores críticos de sucesso citados constantemente na literatura é o apoio da alta administração (Fortune e White, 2006). Assim, a perda desse apoio é fator preponderante no fracasso de um projeto, tal condição foi observada no projeto objeto deste estudo de caso.

Em países em desenvolvimento como o Brasil, o ambiente de projeto apresenta desafios especiais aos seus gerentes. Quase sempre envolvem custos extensos e adicionais detempoantesmesmodeseuinício. Taisdesafios 
são oriundos principalmente de riscos inerentes, tais como: instabilidade política, procedimentos contratuais demasiadamente burocráticos e falta de infraestrutura adequada (redes de transporte, fornecimento de energia elétrica e telecomunicações). Em face a estes problemas singulares, estudos anteriores sugerem a necessidade de desenvolvimento de ferramentas e técnicas de gestão 'adequadas' especificamente adaptado ao ambiente do projeto em países como o Brasil (Faniran et al., 2000).

Como consequência de um cenário de desestruturação interna das empresas contratantes, os projetos podem ser afetados em maior ou menor grau, tanto em desvio de prazo quanto em desvio de custo - extrapolação de tempo e extrapolação de custo, respectivamente (Muianga et al., 2015); com elevada incerteza sobre a continuidade ou não dos trabalhos. Esta condição foi observada no projeto, quando a própria gerência - por parte da empresa projetista - não foi informada das condições da paralisação e nem do período de sua extensão.

Em março de 2015 houve o desligamento, de modo repentino e sumário, motivado por fatos não informados a gerência do projeto, de uma engenheira sênior e do superintendente de infraestrutura (ambos funcionários da alta administração do cliente/ "sponsor" envolvidos diretamente com o dia-a-dia dos trabalhos do projeto). No tocante a comunicação entre o cliente e a projetista, não houve o controle da mesma como processo integrante do gerenciamento das comunicações do projeto, impedindo assim que ela fosse satisfatoriamente coletada, organizada, armazenada e distribuída (Heldman, 2015).

O processo denominado plano de gerenciamento das comunicações descreve o elemento 'frequência das comunicações', que incluiu os intervalos de tempo para a distribuição (Heldman, 2015). Este elemento não esteve presente no plano de gerenciamento da comunicação original do projeto, sendo a comunicação iniciada através de demanda espontânea vinda do cliente, de forma não estruturada (sem frequência bem definida) e com histórico recorrente de transmissão da comunicação sem tempo hábil para tomada de decisões do gerente de projeto e realização da melhor ação a ser tomada.

Os desligamentos citados tiveram um impacto incalculável, uma vez que não foram realizadas substituições e não houve nenhum período de transição dos trabalhos. Define-se transição como período de transmissão dos conhecimentos acerca dos trabalhos desenvolvidos e tratativas com demais "stakeholders" (referido por Project Management Institute [PMI] (2017) como um indivíduo, grupo ou organização que pode afetar, ser afetado ou ter a percepção que pode ser afetado por uma decisão, atividade ou resultado de um projeto). Como estes funcionários citados eram considerados importantes e imprescindíveis "stakeholders" e houve a vacância de cargos na empresa com igual alto grau de envolvimento e poder de decisão destes funcionários, os trabalhos do projeto não puderam avançar, sob pena de altos custos com retrabalho ou, até mesmo, perda dos serviços executado e montantes dispendidos na execução.

Segundo Berssaneti et al. (2014), as preocupações existentes com custo, prazo e qualidade do projeto são tradicionalmente utilizadas como critérios para a medição de sucesso de projetos e ainda são consideradas centrais para a medição de sucesso do mesmo.

A problemática principal relacionada às paralizações de projeto é inserida prioritariamente no campo da restrição de prazo e, indiretamente, na restrição de custo, nas quais estão inseridos todos os projetos (Turner, 1999). Tendo em vista que, segundo Maximiano (2014), os projetos constituem-se de estratégias voltadas para a mudança (visando resolver problemas específicos ou fruir oportunidades apresentadas no momento); as interrupções delongadas, com período de tempo suficientemente grande e capaz de trazer alterações ao ambiente econômico e mercadológico, podem vir a alterar a motivação inicial do projeto. Em casos mais complexos, tais interrupções podem anular a justificativa inicial para execução do mesmo.

Maximiano (2014) cita que as mudanças no percurso e a própria alteração do resultado final têm origem em inúmeras razões. Dentre elas a perda de um recurso importante, como a falência de um fornecedor ou corte do financiamento de um patrocinador. Esta situação foi verificada, visto que a empresa de saneamento local (cliente do projeto) ficou incapacitada de viabilizar financeiramente o suprimento dos requisitos de recursos financeiros do projeto devido a sua condição de arrolada em processo de apuração criminal no âmbito da Operação Lava Jato da Polícia e Ministério Público Federal.

Em ambiente de negócios de países em desenvolvimento, as organizações contratantes (clientes de empresas projetistas) frequentemente experimentam inadequado acesso ao financiamento a curto ou longo prazo para viabilizar seus projetos. Como consequência, tem-se a interrupção do trabalho, nos locais do projeto, até que sejam disponibilizados recursos financeiros suficientes para a retomada das atividades. Como estratégia geral de planejamento do projeto, em fase inicial, as pesquisas e investigações pertinentes às modalidades de financiamento devem ser realizadas simultaneamente com outros trabalhos. Um elevado nível de confiança nestes financiamentos deve ser estabelecido anteriormente ao prosseguimento dos trabalhos. A expertise financeira da empresa contratante deve ser o mais cedo possível envolvida, em fase de inicial do projeto (Faniran et al., 2000). 
Segundo Heldman (2015), os requisitos de recursos financeiros do projeto descrevem a necessidade de financiamento ao longo do mesmo e são derivados da linha de base dos custos. Comumente, o financiamento para um projeto geralmente não é liberado todo de uma vez. Algumas organizações optam por liberarem os fundos em incrementos periódicos (mensais, trimestrais ou anuais) ou até de outra maneira mais adequada ao projeto.

Pode ocorrer, eventualmente, de o fluxo de caixa não acompanhar o ritmo dos gastos. Assim, os requisitos de recursos financeiros do projeto dão conta de mitigar estas diferenças através da liberação de fundos em incrementos baseados na "linha de base dos custos" mais as reservas gerenciais que podem ser necessárias para eventos imprevistos. A "linha de base dos custos" constitui um orçamento com fases de tempo em ordem cronológica, segundo o desenvolvimento do projeto, devendo ser aprovada pelo patrocinador do projeto e seus principais “stakeholders" (Heldman, 2015).

Com a referida linha de base dos custos previamente aprovada, o custo total esperado para um projeto genérico pode ser obtido para um projeto hipotético (Figura 2).

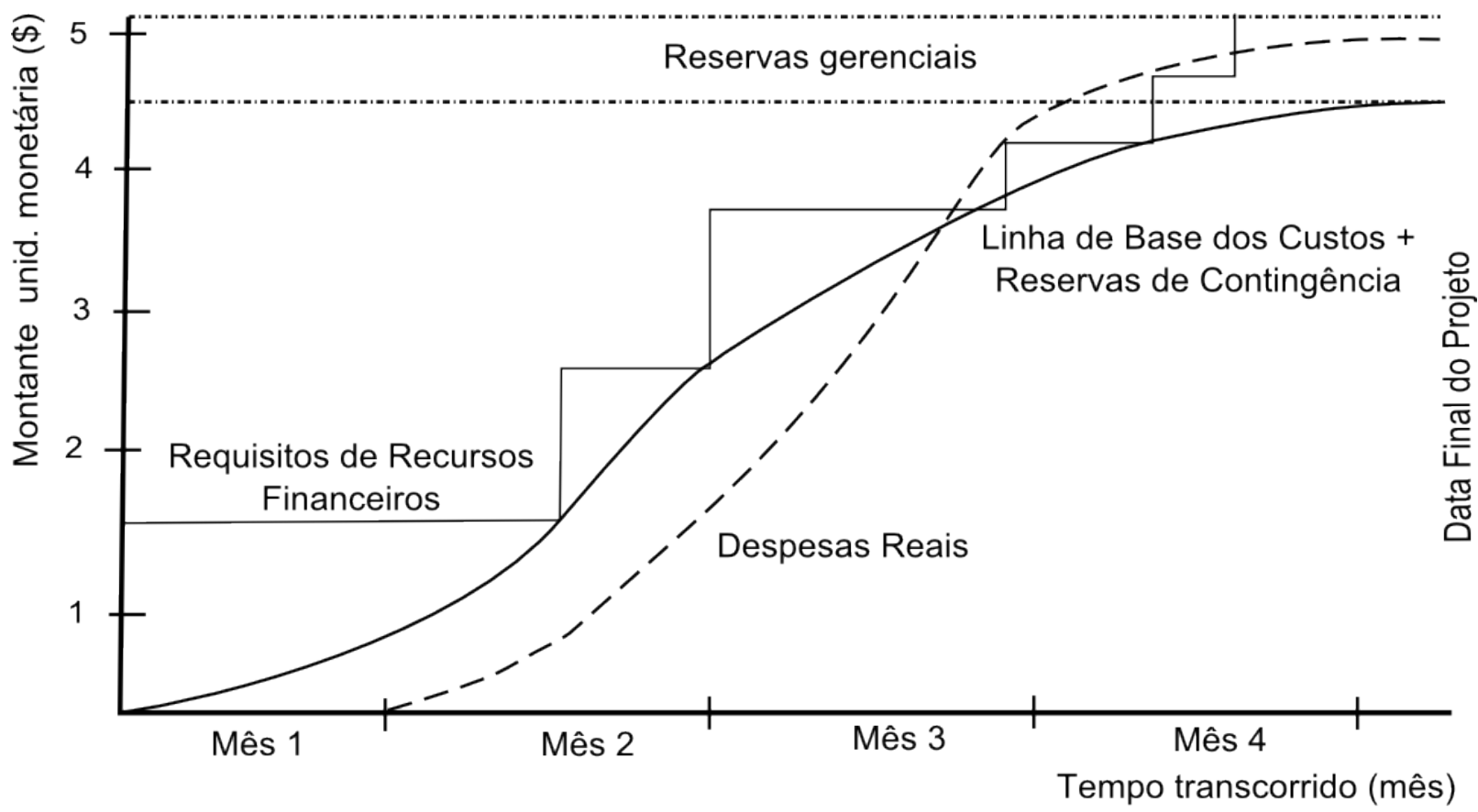

LEGENDA:
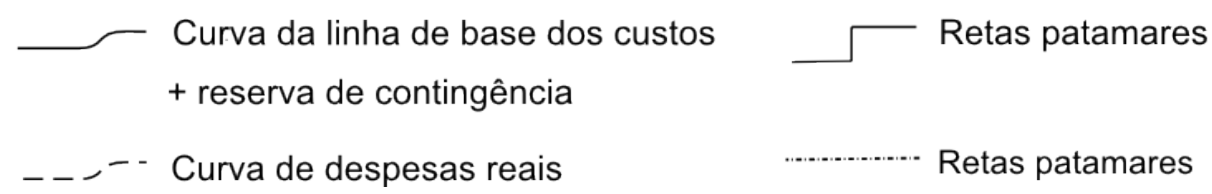

Figura 2. Custo total esperado de projeto hipotético Fonte: Heldman (2015)

A curva da linha de base dos custos (linha sólida); a curva de despesas reais (linha tracejada); os requisitos de recursos financeiros (retas patamares) e faixa de reservas gerenciais (limite superior do gráfico) foram ilustradas na Figura 2. A diferença entre os requisitos de recursos financeiros e a linha de base dos custos no fim do projeto constitui a reserva gerencial (Heldman, 2015). Os requisitos de recursos financeiros devem ser incrementados quando a curva da linha base dos custos atingem os recursos financeiros disponíveis. O momento ideal para esse incremento é uma saída do processo determinar o orçamento (PMI, 2017).

Devido a falta do plano de gerenciamento dos custos como preconizado em PMI (2017), no projeto estudado, não houve coleta dos requisitos de recursos financeiros; $\mathrm{O}$ orçamento dos pacotes de trabalho foi obtido de maneira totalizada, sem ponderação quanto ao desembolso no decorrer do tempo de projeto (elaboração do fluxo de caixa). Assim, bastou existir a dificuldade de obter, via financiamento, o montante necessário ao pagamento da 
totalidade dos gastos inicialmente orçados para que o projeto fosse paralisado; não houve a liberação gradual de financiamento (em incrementos periódicos) de forma a garantir a continuidade normal dos trabalhos.

Com relação à ciência da área de conhecimento do gerenciamento dos riscos do projeto, seus grupos de processo e do planejamento de contingências (PMI, 2017) Heldman (2015) citou que a falta de financiamento, e/ou desvio de fundos para outros projetos, podem ser inseridos na categoria denominada 'Riscos Organizacionais'. O agrupamento dos riscos em categorias representa uma forma de identificar sistematicamente os riscos e serve de base para sua compreensão; uma maneira de escrever as categorias de risco é construindo uma Estrutura Analítica dos Riscos [EAR] (Figura 3), que liste e discrimine as categorias e subcategorias (Heldman, 2015).

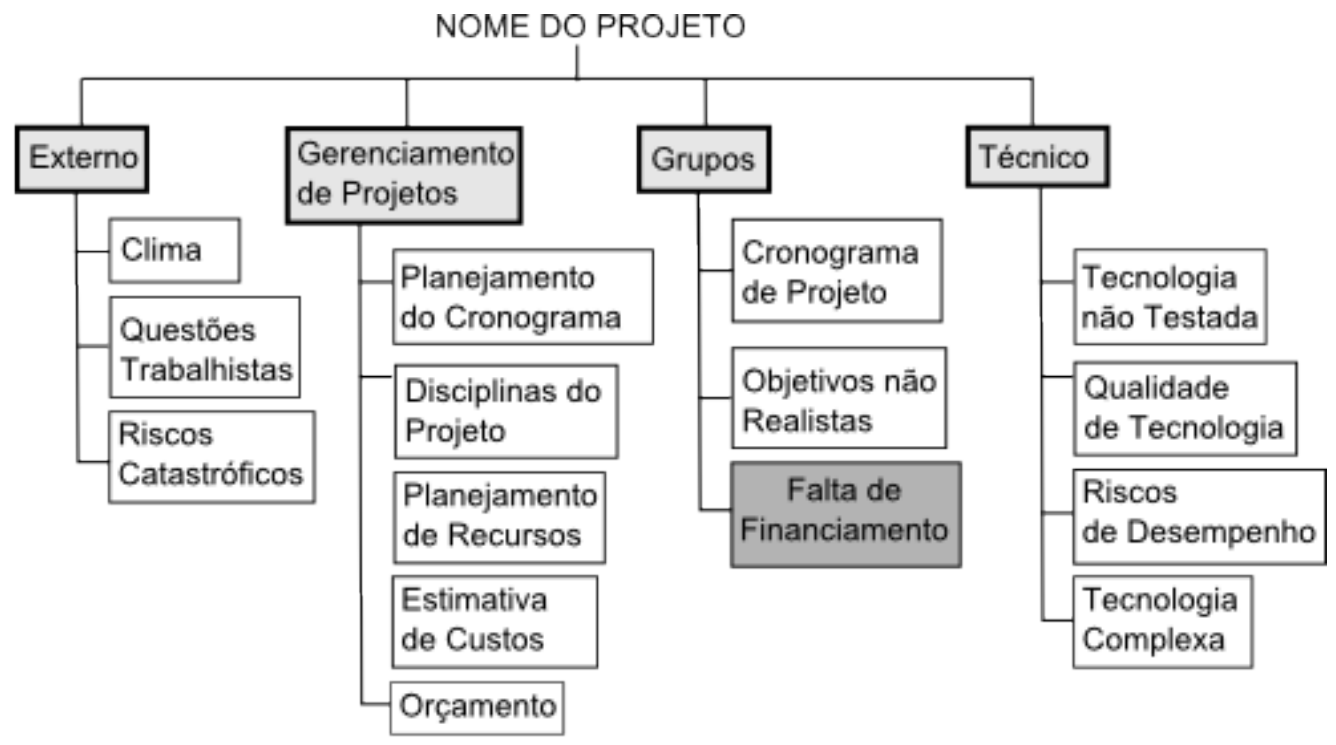

LEGENDA:

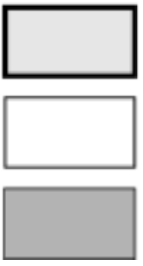

Categoria de Risco

Subcategoria de Risco

Subcategoria de Risco Estudado

Figura 3. Estrutura Analítica dos Riscos típica de projeto com destaque para subcategoria "Falta de Financiamento" Fonte: Heldman (2015)

A EAR apresentada foi organizada em colunas, sob o agrupamento maior ('nome do projeto') cada uma das categorias de risco estudado foi alinhada sobre suas respectivas subcategorias - foram hipoteticamente listadas as subcategorias pertinentes a tipologia do projeto. A montagem da EAR deve ser utilizada como entrada para o processo de administrar os riscos de um projeto, que consiste em antecipar a ocorrência de problemas, como base para o planejamento de respostas e monitorar e controlar a ocorrência de riscos durante a execução do projeto (Maximiano, 2014).

Foi observado, no projeto objeto deste estudo, a falta da elaboração desta importante ferramenta para o planejamento do gerenciamento dos riscos. Consequentemente, o planejamento das respostas aos riscos do projeto não foi realizada a contento e consequentemente não houve controle dos mesmos (PMI, 2017). Houve, em decorrência desta falha na identificação dos riscos (sem a elaboração da análise qualitativa e quantitativa), elevada exposição ao risco político, que acabou materializando-se através das implicações decorrentes da Operação Lava Jato.

\section{Conclusão}

A carência na elaboração de elementos importantes e consagrados da administração de projetos, tais como: Estrutura Analítica de Projeto [EAP], elaboração da linha de base dos custos e coleta dos requisitos financeiros do projeto é fato colaborativo para o fracasso, no que tange o suprimento das necessidades financeiras do projeto. 
O insucesso do referido projeto, acometido de paralização total dos serviços logo após o desligamento de importantes "stakeholders", expõem a necessidade de apoio da alta administração ao projeto e evidencia a importância crucial do engajamento direto dos "stakeholders" chave em casos de desestruturação organizacional.

Com um gerenciamento de comunicação notadamente falho e com a inexistência de um controle efetivo da comunicação do projeto, os acontecimentos externos mais importantes e decisivos - para o bom andamento do projeto - não foram adequadamente transmitidos em tempo hábil. Assim, o planejamento das ações de respostas não foi realizado, expondo os trabalhos a necessidade de paralisação. Fica latente a necessidade de atenção e empenho no processo de planejar o gerenciamento das comunicações do projeto, de sobremaneira em projetos onde os acontecimentos de origem externa são de proporções nunca antes registradas; como no caso das implicações da Operação Lava Jato.

A falta da elaboração do plano do gerenciamento dos riscos (consequentemente sem a elaboração da EAR) acarreta em crítica carência do gerenciamento dos riscos do projeto - os quais devem ser corretamente identificados, analisados e controlados com os seus possíveis efeitos mitigados. Assim, quando há carência de gerenciamento nesta área, os riscos - mesmo que de baixa probabilidade - da severa falta de financiamento durante a execução do projeto não foram identificados. Quando a ocorrência do risco é confirmada nenhum plano de resposta pode ser colocado em prática e, consequentemente, a mitigação não pode ser efetuada. Assim, a continuidade do projeto é criticamente afetada; o mesmo fica susceptível a ser juridicamente encerrado e não cumprir com seu objetivo inicial.

\section{Referências}

Berssaneti, F.T.; Assumpção, A.; Nakao, O.S. 2014 Engenharia e construção: quais variáveis contribuem para o sucesso dos projetos executados atualmente no Brasil? Gestão \& Produção. 21: 95-109

Faniran, O.O.; Love, P.E.D.; Smith, J. 2000. Effective FrontEnd Project Management - A Key Element in Achieving Project Success in Developing Countries. Proceedings of Construction Development Conference. Netherlands, Rotterdam. Disponível em: <http://www.irbnet.de/daten/ iconda/CIB8846.pdf> Acesso em: 15 mar. 2017.

Fortune, J.; White, D. 2006. Framing of project critical success factors by a systems model. International Journal of Project Management 24: 53-65

Heldman K. 2015. Gerência de Projetos: guia para o exame oficial do PMI. Editora Elsevier, Rio de Janeiro, RJ, Brasil.

Maximiano, A.C.A. 2014. Administração de projetos: como transformar ideias em resultados. Editora Atlas, São Paulo,
SP, Brasil.

Miguel, P.A.C. 2007. Estudo de caso na engenharia de produção: estruturação e recomendações para sua condução. Produção 17: 216-229.

Ministério Público Federal [MPF]. 2017. Entenda o Caso. Disponível em: <http://lavajato.mpf.mp.br/entenda-ocaso > Acesso em: 01 mar. 2017.

Muianga, E.A.D.; Granja, A.D.; Ruiz, J.A. 2015. Desvios de custos e prazos em empreendimentos da construção civil: categorização e fatores de influência. Ambiente Construído. Porto Alegre 15: 79-97. Disponível em: <http://www. scielo.br/scielo.php? script $=$ sci_arttext\&pid $=$ S167886212015000100079\&lang=pt $>$ Acesso em: 01 mar 2017.

Project Management Institute [PMI]. 2017. A Guide to the Project Management Body of Knowledge (PMBOK® Guide). 6ed. Project Management Institute, Philadelphia, PA, USA.

Sabbatini, R. 2011. Relatório de Engenharia Consultiva no Brasil - Desafios e Oportunidades. Agência Brasileira de Desenvolvimento Industrial [ABDI]. Disponível em: <http://www.abdi.com.br/Estudo/relatorio_neit_engconsultiva_final.pdf $>$ Acesso em: 11 abr. 2017.

Tribunal De Contas Da União [TCU]. 2017. Responsabilidade Pública - Inidôneos. Disponível em: <http://portal.tcu.gov. $\mathrm{br} /$ responsabilizacao-publica/licitantes-inidoneas/> Acesso em: 01 mar. 2017

Turner, J.R. 1999. The Handbook of Project Based Management. McGraw-Hill Publishing Company, London, England. 